\title{
Dacryocystography of normal and pathological lacrimal passages
}

\author{
S. R. K. MALIK*, A. K. GUPTA*, S. GHATERJEE*, \\ O. P. BHARDWAJ**, AND M. SAHA**
}

Departments of Ophthalmology* and Radiology**, Maulana Azad Medical College and Associated Hospitals, New Delhi, India

Dacryocystography is a method of visualizing the lacrimal passages by the use of radiot opaque contrast media. Ewing (Igog) suggested the use of bismuth subnitrate in liquid petroleum as the contrast medium. Von Szily (1920) described the pathology of the lacrimal passages as seen by roentgenography. Lipoidol was used as the contrast medium by Bollack (1924), lipoidol with olive oil by Spackman (1938), iodized oil by Fox (I947 and Blankstein (1952), ethyl iodophenyl undecylate (Pantopaque) by Milder and Demores (1954) and Demorest and Milder (1955), and neohydriol by Agarwal (I96I) and Nahata (1964).

\section{Material}

The present study was carried out on two groups of individuals:

I. 37 control subjects These were out-patients with no complaint of epiphora. The lacrima passages were found to be patent on syringing.

II. 169 patients complaining of epiphora The condition of the lacrimal passages was assessed b syringing and the results were correlated with those obtained by dacryocystography.

\section{Technique}

0.5 to I ml. concentrated dionosil solution (Saha, Bhardwaj, Malik, and Jain, 1967) was injected into the lacrimal sac through the lower punctum with a $2 \mathrm{ml}$. syringe and cannula. Skiagrams werê taken immediately after the injection in the following positions:

(a) Postero-anterior view The patient lay prone in the nose-chin position with the orbit at an angle of $40^{\circ}$ to the horizontal. The central ray was directed through the infraorbital margin of the injected side, about half an inch lateral to the midline.

(b) Lateral view The patient's head was turned to the injected side; the central ray was directed as in the postero-anterior view.

In each case a Potter-Bucky diaphragm was used.

\section{Observations}

(I) APPEARANCE OF NORMAL DAGRYOGYSTOGRAM

In all the normal subjects the lower canaliculus, lacrimal sac, and nasolacrimal duct werब outlined. The following observations were made:

(a) Canaliculi The lower punctum and the lower canaliculi were visible in all cases 
The canaliculi opened into a common ampulla, the sinus of Maier, in $94 \cdot 6$ per cent. of cases, and separately into the sac in the remainder.

(b) Lacrimal sac This was found to have a smooth outline. A shallow constriction was seen at the junction of the sac and the duct and indicated the location of the valve of Krause.

(c) Nasolacrimal duct In 10.8 per cent. of cases, constrictions in the column of contrast medium in the nasolacrimal duct were seen. These were possibly due to mucosal folds. In the other cases the valves were absent and the duct looked like a smooth tube. In two cases small single diverticula were seen in the lateral wall of the duct. In one case the duct was tortuous.

(d) Measurements of lacrimal sac and nasolacrimal duct The dimensions are summarized in Table I.

Table I Measurements of normal lacrimal passages in 37 cases

Dimension $\quad$ Lacrimal sac $(\mathrm{mm}$.$) \quad Nasolacrimal duct (\mathrm{mm}$.

(I) Vertical diameter

$\begin{array}{lrr}\text { Mean } & 11 \cdot 10 & 20 \cdot 97 \\ \text { S.D. } & \pm 1 \cdot 97 & \pm 3.37 \\ \text { S.E. } & \pm 0.33 & \pm 0.56\end{array}$

(2) Lateral diameter

$\begin{array}{lrr}\text { Mean } & 2 \cdot 43 & 2 \cdot 30 \\ \text { S.D. } & \pm 0.95 & \pm 0.83 \\ \text { S.E. } & \pm 0.16 & \pm 0.14\end{array}$

(3) Antero-posterior diameter

Mean

S.D.

S.E.

$\begin{array}{rr}4 \cdot 00 & 2 \cdot 84 \\ \pm 1 \cdot 49 & \pm 0 \cdot 79 \\ \pm 0.20 & \pm 0.13\end{array}$

(2) CASES WiTH PATHOLOGY OF LAGRIMAL PASSAGES

(a) Clinical particulars

Sex Females were affected more commonly than males (Table II).

Table II Sex incidence of lacrimal passage pathology

\begin{tabular}{lcl}
\hline Sex & Number of cases & Percentage \\
\hline Male & 31 & $18 \cdot 3$ \\
Female & $13^{1}$ & $81 \cdot 7$ \\
\hline
\end{tabular}

Age The average age in females was 35.9 years (range 12-80). The incidence rose steadily to a maximum in the fourth decade. This was followed by a gradual decline.

The average age in males was 23.8 (range $\mathrm{I}_{\mathrm{I}}-72$ ). The highest incidence occurred in the late twenties.

The age incidence in the two sexes is shown in Fig I (overleaf). 


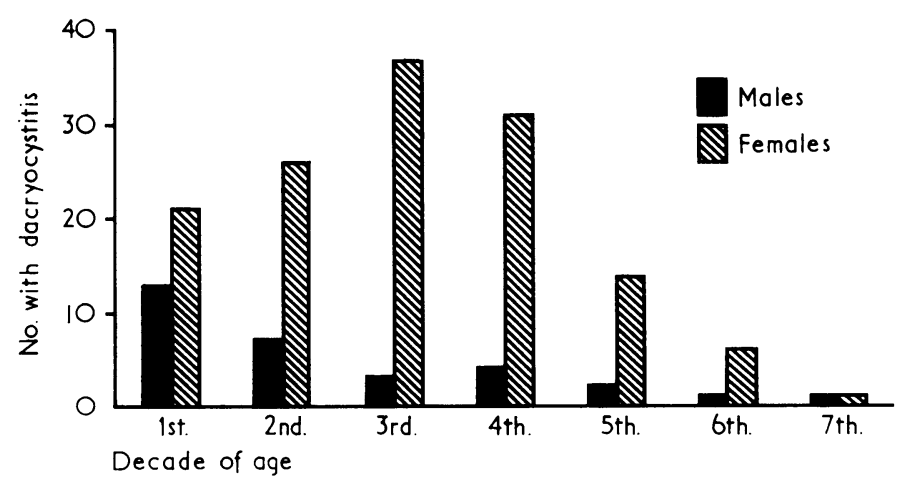

FIG. I Age incidence of $\frac{\bar{\sigma}}{\frac{0}{5}}$ pathological findings, by sex $\overrightarrow{\mathbb{D}}$

Side involved The left side $(99 ; 58.8$ per cent.) was more commonly involved than the right $(70 ; 4 \mathrm{I} \cdot 2$ per cent.).

(b) Radiological appearances (Figs 2 to 6)

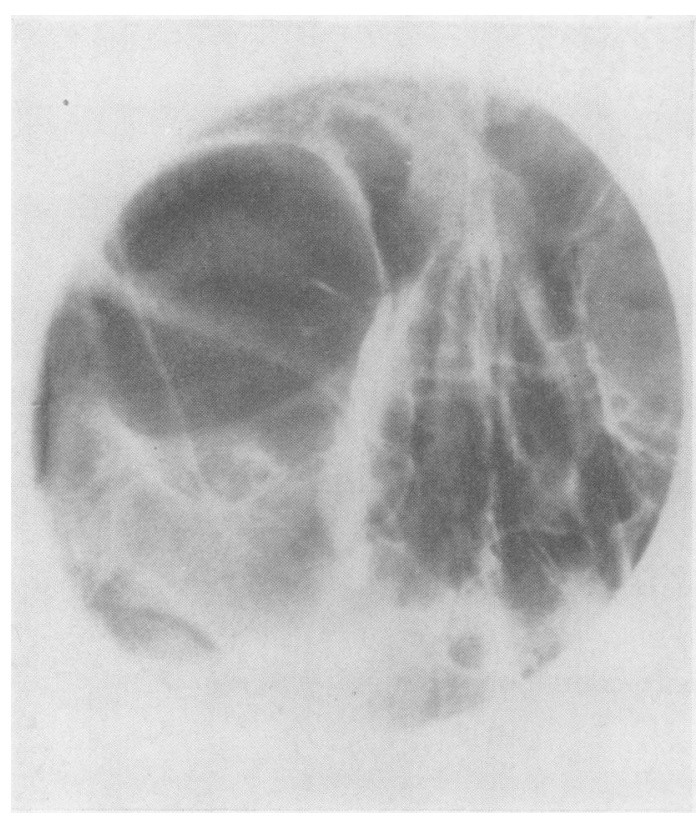

FIG. 2 Normal dacryocystogram for comparison with

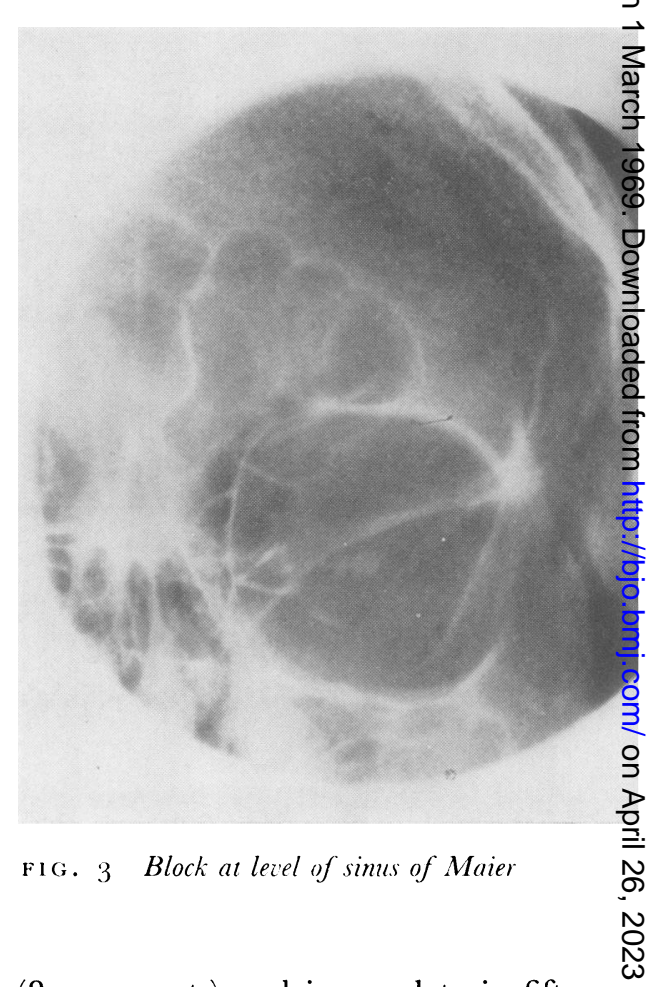

Obstruction This was complete in I 35 cases (8o per cent.) and incomplete in fifteen (8.8 per cent.). In nineteen cases ( I I.2 per cent.) there was no obstruction. Theseco observations agree with those of Nahata (1964).

The commonest site of obstruction was the junction of the lacrimal sac and the naso- $\stackrel{+}{+}$ lacrimal duct (ninety cases; 53.2 per cent.), and the next commonest site was the sinus of $\frac{0}{0}$ Maier (4I cases; $24 \cdot 3$ per cent.). This observation agrees with that of Campbell (I 964$)$ ) $\stackrel{\mathbb{Q}}{Q}$

Condition of the sac In ten cases the dimensions were nearly normal, nineteen had $\stackrel{\mathbb{D}}{\mathbb{Q}}$ small irregular sacs, and seventy showed dilatation (49 in all dimensions including the 

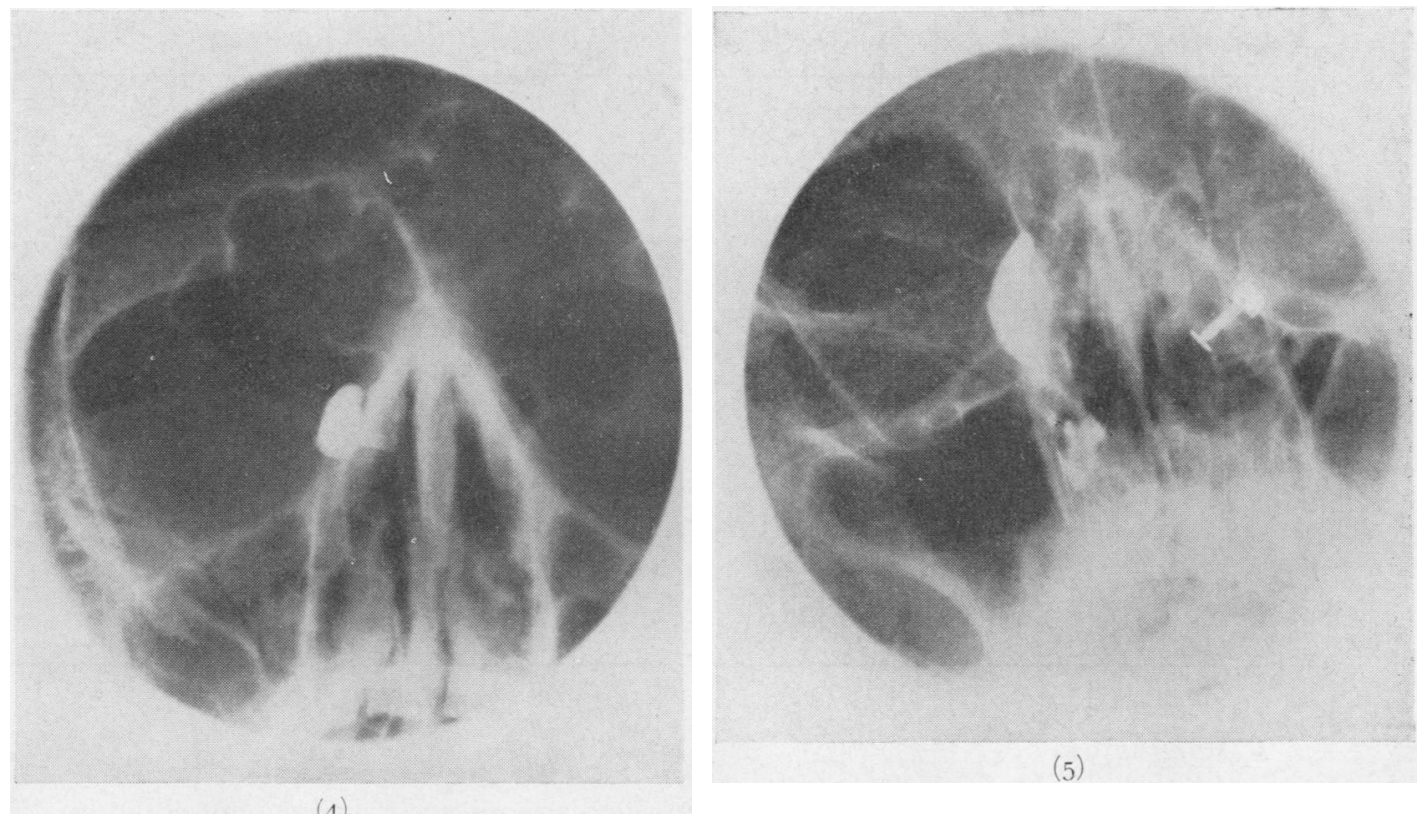

(4)

FIG. 4 Mucocele of lacrimal sac with obstruction at junction of sac and duct

FIG. 5 Mucocele of the lacrimal sac with partial block at junction of sac and duct. Some of the dye can be seen in the nasal cavity

FIG. 6 Mucocele of lacrimal sac with diverticula

vertical, and $2 \mathrm{I}$ in the lateral and antero-posterior diameters only, with reduction in the vertical diameter).

Abnormalities of the sac There were fourteen diverticula; in only one case were multiple diverticula seen on both sides. In all cases the diverticula were in the lateral wall, above and laterally (10) or below and laterally (4).

There were seven external fistulae (4.I per cent.) and none internal.

There were no cases of filling defect.

(c) Measurements of the sac

These are shown in Table III (overleaf). 
Table III Measurements of the lacrimal sac in normal controls and pathological conditions

\begin{tabular}{|c|c|c|c|c|c|c|}
\hline \multirow[b]{2}{*}{ Dimensions } & & \multirow[b]{2}{*}{ Normal control } & \multirow[b]{2}{*}{$\begin{array}{l}\text { Cases with near } \\
\text { normal } \\
\text { dimensions } \\
10(11 \cdot 1 \%)\end{array}$} & \multicolumn{2}{|c|}{ Cases with dilatations $70(77.8 \%)$} & \multirow{2}{*}{$\begin{array}{l}\text { Cases with } \\
\text { small shrunken } \\
\text { sacs } \\
\text { I0 }(\mathrm{I} \mathrm{I} \cdot \mathrm{I} \%)\end{array}$} \\
\hline & & & & $\begin{array}{l}\text { Dilatations in } \\
\text { all dimensions } \\
49(54.4 \%)\end{array}$ & $\begin{array}{l}\text { Dilatation in } \\
\text { antero-posterior } \\
\text { and transverse } \\
\text { diameters } \\
21(23.4 \%)\end{array}$ & \\
\hline Vertical diameter & $\begin{array}{l}\text { Mean } \\
\text { S.D. } \\
\text { S.E. }\end{array}$ & $\begin{array}{l}\text { I I. IO } \mathrm{mm} \\
\pm \mathbf{I} \cdot 97 \\
\pm 0 \cdot 33\end{array}$ & $\begin{aligned} & 8 \cdot 9 \\
+ & I \cdot 51 \\
\pm & 0 \cdot 50\end{aligned}$ & $\begin{array}{l}12 \cdot 9 \\
\pm 2 \cdot 92 \\
\pm 0 \cdot 4^{2}\end{array}$ & $\begin{array}{c}7 \cdot 0 \\
\pm 1 \cdot 14 \\
\pm 0 \cdot 25\end{array}$ & $\begin{aligned} & 4 \cdot 5 \\
+ & 2 \cdot 91 \\
\pm & 0 \cdot 31\end{aligned}$ \\
\hline Lateral diameter & $\begin{array}{l}\text { Mean } \\
\text { S.D. } \\
\text { S.E. }\end{array}$ & $\begin{aligned} & 2.43 \mathrm{~mm} . \\
\pm & 0.95 \\
\pm & 0.16\end{aligned}$ & $\begin{array}{r}1.95 \\
\pm 0.52 \\
\pm 0.16\end{array}$ & $\begin{array}{r}5 \cdot 98 \\
\pm 2 \cdot 48 \\
\pm 0 \cdot 36\end{array}$ & $\begin{array}{r}4.4 \\
\pm 0.82 \\
\pm 0.18\end{array}$ & $\begin{aligned} & 2 \cdot 6 \\
\pm & 0 \cdot 91 \\
\pm & 0 \cdot 30\end{aligned}$ \\
\hline $\begin{array}{l}\text { Antero-posterior } \\
\text { diameter }\end{array}$ & $\begin{array}{l}\text { Mean } \\
\text { S.D. } \\
\text { S.E. }\end{array}$ & $\begin{aligned} & 4 \cdot 00 \mathrm{~mm} \\
\pm & \mathrm{I} \cdot 49 \\
\pm & 0 \cdot 20\end{aligned}$ & $\begin{aligned} & 2 \cdot 9 \\
+ & 1 \cdot 04 \\
\pm & 0 \cdot 34\end{aligned}$ & $\begin{array}{r}7.02 \\
+2.59 \\
\pm 0.36\end{array}$ & $\begin{aligned} & 5 \cdot 1 \\
\pm & 1 \cdot 17 \\
\pm & 0 \cdot 26\end{aligned}$ & $\begin{aligned} & 2 \cdot 6 \\
+ & 0.66 \\
\pm & 0.22\end{aligned}$ \\
\hline
\end{tabular}

\section{Discussion}

Dacryocystography is a valuable aid in the diagnosis and management of lacrimal passage pathology. It reveals the living anatomy of the passages, changes due to disease, and th $\overrightarrow{\mathrm{e}}$ relationship of functional impairment to structural abnormalities.

One of the chief problems discussed by workers in this field has been the selection of ideap radio-opaque contrast media. Oily media have the disadvantage of globule formations and may produce artefacts, and aqueous material is usually too thin to be retained while the radiological procedure is completed. Saha and others (1967) overcame this difficult by using a very high concentration of dionosil in an aqueous base.

Our study of dacryocystograms in normal subjects enabled us to establish standarç normal radiological appearances and measurements. These closely coincided with the dimensions reported in the text-books of anatomy (Duke-Elder, I96I) (Table IV).

Table IV Relationship of normal lacrimal passage dimensions in the present series to those given in anatomical text books

\begin{tabular}{|c|c|c|c|c|c|}
\hline \multirow{2}{*}{ Area } & \multirow{2}{*}{$\begin{array}{l}\text { Dimension }(\mathrm{mm} .) \\
\text { Vertical diameter } \\
\text { Lateral diameter } \\
\text { Antero-posterior diameter }\end{array}$} & \multicolumn{2}{|c|}{$\begin{array}{l}\text { Present study } \\
\text { Mean Range }\end{array}$} & \multicolumn{2}{|c|}{$\begin{array}{l}\text { Anatomical text books } \\
\text { Mean Range }\end{array}$} \\
\hline & & $\begin{array}{r}11 \cdot 10 \\
2 \cdot 43 \\
4 \cdot 00\end{array}$ & $\begin{array}{l}6-14 \\
I-4 \\
I-6\end{array}$ & $\begin{array}{l}12 \\
-\end{array}$ & $\begin{array}{l}- \\
2-3 \\
4-8\end{array}$ \\
\hline $\begin{array}{l}\text { Nasolacrimal } \\
\text { duct }\end{array}$ & $\begin{array}{l}\text { Vertical diameter } \\
\text { Lateral diameter } \\
\text { Antero-posterior diameter }\end{array}$ & $\begin{array}{r}20 \cdot 97 \\
2 \cdot 30 \\
2 \cdot 84\end{array}$ & $\begin{array}{l}3-26 \\
I-4 \\
I-4\end{array}$ & $\stackrel{17 \cdot 7}{-}$ & - \\
\hline
\end{tabular}

We observed an obstruction at the level of the sinus of Maier in 24.3 per cent. of cases? but Nahata (1964) and Gastrén and Korhonen (1964) found this in only 5.7 and I 5 peE cent. respectively.

The information obtained about the site of the obstruction, the size and shape of the sac and the presence of diverticula and fistulae was a great help in case management. 
Other observations were made in the course of the study. The left side was involved more commonly than the right, and the dacryocystitis was more common in women than in men (approximately $4: 1$ ). The latter is probably due to the narrower lumen of the lacrimal passages in females.

The peak incidence for females occurred in the forties while males showed a preponderance in the late twenties. The difference may be caused by the fact that specific infections are more common in males while females may suffer from chronic irritation such as that caused by smoke, etc., while cooking.

\section{Summary}

Dacryocystography was carried out in 37 normal subjects and 169 patients complaining of epiphora. Concentrated dionosil aqueous was found to give satisfactory results. The normal measurements for the lacrimal passages for Indian subjects have been determined. The value of routine dacryocystography before surgery is discussed.

\section{References}

agarwal, m. L. (196i) Amer. 7. Ophthal., 52, 245

blankstein, s. s. (1952) A.M.A. Arch. Ophthal., 48, 322

Bollack, J. (1924) Ann. Oculist., 161, 32 I (cited by Duke-Elder, I96 I)

CAMPBell, w. (1964) Brit. J. Radiol., 37, I

CASTRÉn, J. A., and KORHONEN, м. (1964) Acta ophthal. (Kbh.), 42, I88

DEMOREST, B. H., and MiLDER, B. (1955) A.M.A.Arch. Ophthal., 54, 4 Io

DUKE-ELDER, s. (I96I) “System of Ophthalmology", vol. 2, p. 572 . Kimpton, London

EWING, A. E. (1909) Amer. 7. Ophthal., 26, I

FOX, S. A. (1947) Ibid., 30, 878

MILDER, B., and DEMOREST, B. H. (1954) A.M.A. Arch. Ophthal., 51, I80

nahata, м. C. (1964) Amer. 7. Ophthal., 58, 490

SAHA, M., BHARDWAJ, O. P., MALIK, s. R. K., and JAIN, s. K. (1967) Indian F. Radiol., 21, No. 1, p. 13

SPACKMAn, E. W. (1938) Amer. F. Ophthal., 21, 518

sZILy, A. von (1920) Klin. Mbl. Augenheilk., 64, 31 